\title{
Deteksi Cacing Nematoda Pada Ayam Kampung (Gallus domesticus) Di Desa Bagikpayung Kecamatan Suralaga Kabupaten Lombok Timur
}

\author{
Detection Of Worm Nematode In Gallus domesticus In Bagik Payung Village, Suralaga \\ District, East Lombok Regency
}

\author{
Febi Kurnia ${ }^{1 *}$, Candra Dwi Atma ${ }^{2}$, Novarina Sulsia Ista'In Ningtyas ${ }^{3}$, Maratun Janah ${ }^{4}$ \\ ${ }^{1}$ Asisten Laboran Dinas Peternakan Kabupaten Lombok Timur, ${ }^{2}$ Dosen Divisi Mikrobiologi dan \\ Parasitologi, ${ }^{3}$ Dosen Divisi Anatomi dan Patologi Veteriner, ${ }^{4}$ Dosen Divisi Produksi dan Reproduksi \\ Veteriner \\ Fakultas Kedokteran Hewan, Universitas Pendidikan Mandalika \\ *Corresponding author: dokterfebi@gmail.com
}

\begin{abstract}
Abstrak
Ayam kampung merupakan salah satu unggas yang memiliki cukup banyak manfaat untuk kehidupan manusia sebagai bahan pangan. Infeksi cacing nematoda memiliki angka kematian yang rendah, namun memiliki efek langsung pada produktivitas dan akan menggangu kesehatan masyarakat. Telah dilakukan penelitian pada Ayam Buras di Desa Bagik Payung Kecamatan Suralaga Kabupaten Lombok Timur dengan tujuan untuk mendeteksi cacing nematoda pada Ayam Kampung. Sampel yang diambil sebanyak 10 feses Ayam Buras dan diperiksa dengan metode natif dan apung dilaboratorium Equine Clinical Skills Center (CSC) Fakultas Kedokteran Hewan Universitas Pendidikan Mandalika Mataram kemudian diidentifikasi berdasarkan morfologinya. Hasil didapatkan 3 sampel positif terinfeksi cacing golongan nematoda. Hasil deteksi jenis cacing nematoda yang menginfeksi Ayam Buras yaitu jenis Capillaria sp. Berdasarkan penelitian ini dapat disimpulkan bahwa Ayam Buras di Desa Bagik Payung Kecamatan Suralaga Kabupaten Lombok Timur terinfeksi endoparasit cacing.
\end{abstract}

Kata kunci: Ayam Kampung, Nematoda, Helminthiasis

\section{Abstract (In English)}

Domestic chicken (Gallus domesticus) is one of the poultry that has quite a lot of benefits for human life as food. Nematode infection has a low mortality rate, but has a direct effect on productivity and will be detrimental to public health. Research has been carried out on in Gallus domesticus Bagik Payung Village, Suralaga District, East Lombok Regency with the aim of detecting nematode in Gallus domesticus. Samples were taken as many as 10 Gallus domesticus feces and examined by native and floating methods in the Laboratory Faculty of Veterinary Medicine Mandalika Mataram University of Educationand then identified based on their morphology. The results obtained 3 positive samples infected with nematode. The results of the detection of nematode that infect Gallus domesticus are Capillaria sp. Based on this research, it can be concluded that Gallus domesticus in Bagik Payung Village, Suralaga District, East Lombok Regency is infected with worm endoparasites.

Keywords: Gallus domesticus, Nematoda, Helminthiasis 


\section{Pendahuluan}

Ayam kampung (Gallus

domesticus) merupakan salah satu jenis ternak unggas yang telah mengalami domestikasi dan tersebar di seluruh pelosok nusantara. Ayam kampung mempunyai peran yang sangat besar bagi kehidupan masyarakat terutama di pedesaan, karena dapat dimanfaatkan sebagai sumber daging dan telur serta sebagai tambahan pendapatan (Solihati dkk., 2006). Seperti yang ada di Desa Bagik Payung, Kecamatan Suralaga, Kabupaten Lombok Timur yang mayoritas penduduknya beternak ayam kampung secara ekstensif atau dengan sistem ayam dibiarkan mencari pakan sendiri di sekitar pekarangan rumah, sistem pemeliharaan yang seperti ini menjadikan ayam kampung mudah terinfeksi parasit helminth atau cacing secara alami ditemukan pada berbagai jenis unggas liar dan unggas peliharaan. Parasit yang sering menginfeksi unggas peliharaan seperti bebek, itik, burung dan ayam adalah Nematoda (Cynthia et al., 2009). Penyebaran cacing nematoda terhadap hewan ternak dapat melewati pakan, air, dan peralatan ternak (Parede et al., 2005). Kasus nematoda jenis Ascaridia Galli di laporkan oleh Mukaratirwa et al, (2001) sebesar $64,8 \%$ ditemukan pada survay nematoda di pedesaan Zimbabwe.

Prevalensi Ascaridia galli sebesar $(34,4 \%)$ juga ditemukan pada ayam kampung di Jeddah (Dehlawi, 2007). Hasil penelitian di Indonesia juga menunjukkan kasus cacing nematoda cukup tinggi, cacing nematoda jenis A.galli paling banyak menginfeksi ayam kampung di Kecamatan Kupang Tengah Kabupaten Kupang sebesar 88,58 \%. Penelitian Ananda (2017) di Lampung Prevalensi nematoda pada ayam kampung sebesar $43 \%$.

Helminthiasis pada unggas disebabkan oleh cacing, yang secara umum terdiri dari tiga klas, yaitu klas Nematoda, Trematoda dan Cestoda. Penyakit helminthiasis akibat cacing
Nematoda disebut nematodosis.

Keberadaan cacing nematoda di dalam tubuh ayam kampung dapat menyebabkan kerusakan pada organ-organ tertentu. Penyakit helminthiasis pada ayam kampung merupakan penyakit yang dapat mempengaruhi produktivitas ayam kampung dan umumnya tidak menimbulkan kematian, tetapi bersifat menahun yang dapat mengakibatkan kekurusan, lemah, dan turunnya produksi (Levine, 1994). Infeksi cacing nematoda dapat menghambat pertumbuhan dan mengakibatkan penurunan produksi ayam kampung sehingga menyebabkan pasokan ayam akan kebutuhan masyarakat menurun (Sundaryani, 2007) sehingga menyebabkan kerugian secara ekonomi.

Penelitian tentang nematodosis pada ayam kampung sudah banyak dilakukan, tetapi pada peternak tradisional di wilayah desa bagek payung kecamatan suralaga kabupaten Lombok timur belum pernah dilakukan. Penelitian ini penting untuk dilakukan karena tingkat infeksi cacing nematoda di Indonesia masih tergolong tinggi namun kurangnya informasi dan pengetahuan masyarakat yang menyebabkan sulitnya penanganan dan pengendalian penyakit nematodosis

\section{Materi dan Metode}

\section{Jenis dan Rancangan Penelitian}

Penelitian ini berjenis epidemiologi deskriptif dengan tipe studi potong lintang (Cross Sectional Study) studi potong lintang yang tergolong observasional deskriptif adalah studi yang mendeskripsikan distribusi penyakit dalam penelitian ini bertujuan untuk mengidentifikasi adanya cacing nematoda pada usus ayam kampung

\section{Waktu dan Tempat Penelitian}

Penelitian ini dilaksanakan pada bulan april 2021. Pengambilan sampel bertempat di dusun reriu, dusun bantek, dusun bongak, dusun tumbu, dusun kulur, dusun borok dan dusun dasan baru. Pemeriksaan sampel feses dilakukan di Equine Clinical Skills Center (CSC) 
Fakultas Kedokteran Hewan Universitas Pendidikan Mandalika.

Pengambilan sampel dilakukan secara acak dari 5 dusun di desa bagik payung dengan metode random sampling. Sampel feses yang diambil adalah sampel feses yang masih segar yang dikeluarkan oleh ayam saat malam sampai pagi hari. Sampel yang diambil dimasukkan ke dalam kantong plastik kemudian ditutup rapat dan diberi label. Sampel kemudian dibawa ke laboratorium untuk diperiksa

\section{Metode Pemeriksaan Natif}

Sebanyak 1 gr sampel ditimbang dan dimasukkan ke dalam mortir. Sampel ditambahkan aquades sampai larut. Sampel digerus perlahan kemudian dimasukkan kedalam tabung reaksi sambil disaring. Sampel yang sudah dihomogenkan selanjutnya diteteskan 1 sampai 2 tetes diatas objek glass. Sampel kemudian ditutup dengan cover glass secara perlahan dan diamati di bawah mikroskop menggunakan pembesaran lemah (10X4) sampai pembesaran kuat (10x100).

\section{Pemeriksaan Menggunakan Metode Apung Dengan Sentrifugasi}

Sampel dari pemeriksaan natif diambil sebanyak 5-7 $\mathrm{ml}$ dan dimasukkan ke dalam tabung reaksi (15ml). sampel yang telah dihomogenkan kemudian disentrifuse selama 5 menit dengan kecepatan 1500 rpm, sampai mendapatkan hasil supernatant yang jernih. Sampel kemudian dikeluarkan dari sentrifuse dan supernatan pada tabung dibuang. Sisa endapan pada tabung reaksi kemudian ditambahkan larutan gula jenuh sampai 2/3 tabung. Sampel kemudian dihomogenkan dan disentrifuse kembali dengan kecepatan 4000 rpm selama 5 menit. Sampel dikeluarkan dari sentrifuse dan diletakkan di atas rak tabung reaksi dan ditambahkan Tabel 1 Telur cacing yang teridentifikasi dari 10 sam gula jenuh hingga permukaan tabung berbentuk cembung. Setelah itu cover glass diletakkan di atas tabung kemudian dibiarkan selama 5 menit, setelah itu cover glass diambil dan diletakkan di atas objek glass dan diperiksa di bawah mikroskop dengan pembesaran lemah (10x4) sampai pembesaran kuat (10x100). ( Murray., dkk 2009).

Telur cacing bila sudah ditemukan maka dilakukan identifikasi dengan merujuk pada buku yang berjudul Veterinary Parasitology dan Diagnosing Helminthiasis By Coprogical Examination.

\section{Analisis Data}

Data hasil penelitian ini disajikan dalam bentuk tabel dan gambar seluruh data kemudian dianalisis secara deskriptif sesuai dengan morfologinya adapun kesimpulan ditarik secara deduktif dengan memaparkan hal-hal yang bersifat umum ke khusus.

\section{Hasil dan Pembahasan}

Berdasarkan hasil penelitian pada feses ayam kampung sebanyak 10 sampel yang di ambil di Desa Bagik Payung Kecamatan Suralaga Kabupaten Lombok Timiur terdapat 3 sampel positif dan yang lainnya dinyatakan negatif. Pemeriksaan laboratorium menggunakan metode natif dan metode apung dengan sentrifugasi untuk mengidentifikasi jenis-jenis telur cacing saluran pencernaan pada ayam kampung.

Hasil deteksi telur cacing diketahui melalui morfologi telur cacing yang nampak pada mikroskop. Telur cacing saluran pencernaan pada ayam kampung yang ditemukan pada penelitian ini yaitu telur cacing nematoda jenis Capillaria sp yang diperoleh dari dusun reriu dan dusun bantek. Sesuai dengan tabel 1 berikut.

\begin{tabular}{llc}
\hline Dusun & Jenis Telur Cacing & Jumlah Sampel Positif \\
\hline Reriu & Capillaria $s p$. & 2 \\
Bantek & Capillaria $s p$. & 1 \\
\hline
\end{tabular}




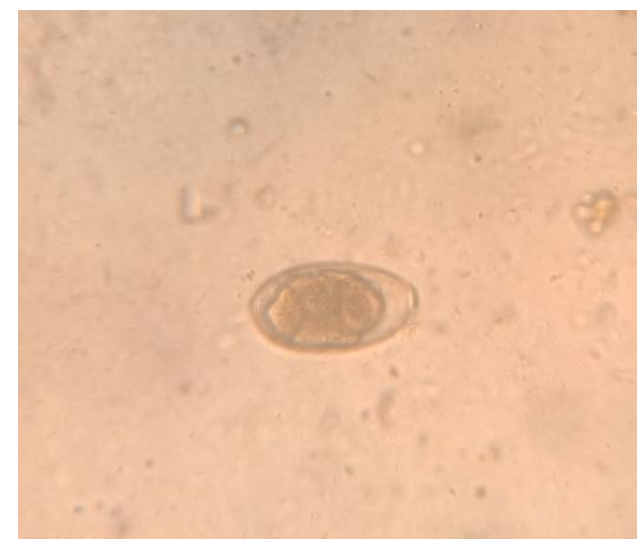

Gambar 1. Telur cacing Capillaria Sp

Berdasarkan hasil pemeriksaan feses yang dilakukan di laboratorium dengan menggunakan dua metode yaitu metode apung dan metode natif, 3 dari 10 sampel feses ayam yang ditemukan 1 telur cacing nematoda jenis Capillariasp. Sampel positif diperoleh dari Dusun Reriu sebanyak 2 sampel positif dan 1 sampel positif diperoleh dari Dusun Bantek. Infeksi telur cacing jenis Capillariasp merupakan telur cacing yang ditemukan dalam pemeriksaan. Ukuran telur cacing Capillaria sp berkisar antara (23.3-68.2 x 12.1,-35.8) $\mu \mathrm{m}$. Menurut Yabsley (2008) telur cacing Capillaria sp mencapai tahap infektif (L2) membutuhkan waktu 10 sampai 20 hari atau lebih, telur cacing ini juga mudah dikenali oleh karakteristik bipolar plug. Siklus hidup beberapa spesies capillaria sp secara langsung (C. obsiganata, C. anatis dan C. contorta). Telur bersama feses dan berkembang menjadi larva tahap pertama dalam 9-14 hari. Pada siklus hidup langsung telur yang tertelan menetas dalam usus dan berkembang menjadi cacing dewasa tanpa migrasi dalam inang. Adapun siklus hidup tidak langsung telur ditelan oleh cacing tanah dan berkembang menjadi tahapan infektif dalam 14-21 hari.

Menurut Smith (1993, 1996), infeksi usus Capillaria sp biasanya tanpa gejala, tapi dengan infeksi berat ayam kampung dapat menunjukkan tanda-tanda klinis seperti diare, anoreksia, kekurusan dan kelesuan. Hal ini sesuai dengan pengamatan yang dilakukan pada penelitian ini yaitu sampel yang positif terinfeksi Capillaria sp tidak menunjukkan gejala.

Sampel yang positif terinfeksi Capillaria sp merupakan anak ayam yang berumur 4 bulan dan 5 bulan hal ini sesuai dengan kerentanan anak ayam yang mudah terinfeksi kecacingan apalagi mayoritas penduduk di Desa Bagik Payung beternak ayam kampung secara ekstensif atau dengan sistem ayam dibiarkan mencari pakan sendiri di sekitar pekarangan rumah, sistem pemeliharaan yang seperti ini berpotensi meningkatkan terjadi resiko infeksi cacing nematoda.

\section{Kesimpulan}

Hasil penelitian deteksi cacing nematoda pada ayam kampung (gallus domesticus) di Desa Bagik Payung Kecamatan Suralaga Kabupaten Lombok Timur. Pengujian sampel dengan menggunakan metode apung dan natif, dari 10 sampel 3 sampel positif. Jenis telur cacing yang ditemukan adalah telur cacing Capillaria sp.

\section{Ucapan Terima Kasih}

Terima kasih Kepada semua pihak yang telah membantu kelancaran pembuatan artikel ilmiah ini.

\section{Daftar Pustaka}

Ananda RR. Rosa E dan Pratami. 2017. Studi Nematoda pada ayam di 
Peternakan Mandiri Kelutahan Tegal Sari. Kecamatan Gading rejo Kab. Pringgasewu Lampung.

Cynthia D, Kelly J, Felles T, Michael WD, 2009, Trematode Flukes (Echinostoma revolutum). Olympus MIC-D: Darkfiel Gallery-trematode Flukes (Echinostoma revolutum).

Dehlawi M S., 2007, The occurrence of Nematodes in the intestine of local (baladi) Chicken (Gallus gallus domesticus) in Jeddah Province. Saudi Arabia. Scientific Journal of King Faisal University. Vol 8(2)

Devi Y.J.A. Moenek dan Aven B. Oematan, 2017. Endoparasit Pada Usus Ayam Kampung (Gallus Domesticus)

Lawson, J.L. and M.A. Gemmel. 1983. Transmission in Hydatidosis and Cysticercosis. Adl arice it1 Para.sitology, 2a: 279.

Levine N D. 1995. Buku Pelajaran Parasitologi Veteriner. Gatot Ashadi, penerjemah; Wardiarto, editor. Terjemahan dari: Textbook Veterinery Parasitology. Gadjah Mada University Press. Yogyakarta.354 - 363.

Levine N D., 1994., Buku Pelajaran Parasitologi Veteriner. Gatot Ashadi, Penerjemah; Wardiarto,editor. Terjemahan dari: Textbook Veterinery Diserang. Jakarta: Penerbit Buku Kedokteran EGC

Levine. N.D, 1990. Parasitologi Veteriner. Terjemahan Gatut Ashadi. Gadjah Mada University Press.

Michele Chandra ,Ida Ayu Pasti Apsari ,I Nyoman Sulabda, 2017. Prevalensi dan Intensitas Infeksi Cacing Tetrameres Spp. pada Ayam Buras di Wilayah Bukit Jimbaran. Badung

Morgan, B.B and P.A. Hawkins, 1960. Veterinary Helminthology. 6th Ed.
Burgess Publishing Company. Minneapolis. USA

Muhamad Cahadiyat Kurniawan,Erna Suzanna, dan Elok Budi Retnani, 2010. Inventarisasi Cacing Parasitik Saluran Pencernaan Pada Elang Jawa (Spizaetus Bartelsi Stressman, 1924) Dan Elang Brontok (Spizaetus Cirrhatus Gmelin, 1788) Di Habitat Eks-Situ

Murray, R. K., Granner, D. K., \& Rodwell, V. W. 2009. Biokimia harper Jakarta: Buku Kedokteran (27 ed.).

Nughroho, 1983. Penyakit Ayam di Indonesia.Jilid II. Eka Offset. Jakarta.

Parede L, Zainuddin D, dan Huminto $\mathrm{H}$. 2005. Penyakit Menular pada Intensifikasi Unggas Lokal dan Cara Penanggulangannya. Lokakarya Nasional Inovasi teknologi Pengembangan Ayam Lokal. Bogor

Smith SA. 1993. Diagnosis and Treatment of Helminths in Birds of Prey. Didalam: Redig PT, Cooper JE, Remple JD, HunterDB, editor. Raptor Biomedicine. University of Minnesota Press. Minneapoliss.

Smith SA. 1996. Parasites of Birds of Prey: Their Diagnosis and Treatment. Seminars in Avian and Exotic Pet Medicine, Vol 5, No 2 April, 1996: pp 97-105.

Soeprapto dan Soetijono, 1989. ParasitParasit Ayam. PT. Gramedia. Jakarta.

Solihati N., R. Idi, R. Setiawan, I.Y. Asmara,dan B.I. Sujana. 2006. Pengaruh Lama Penyimpanan semen cair ayam buras pada suhu $5^{\circ} \mathrm{C}$ terhadap periode fertile dan fertilisasi sperma. J. Ilmu Ternak $6(1): 7-11$

Sulistyati, M. , K. Hidayat, dan D. Garnida. 2001. Produktivitas Ayam Buras Hasil Seleksi Berdasarkan 
Pengetahuan Lokal Peternak.

Jatinangor, Bandung 40600. 3(1):46

-53 .

Sundaryani T. 2007. Teknik Vaksinasi dan Pengendalian Penyakit Ayam.

Penebar Swadaya. Jakarta

Supan Kusumamihardja, 1992. Parasit dan Parasitosis pada Hewan Ternak Piaraan di Indonesia.

Thienpont, D., Frans Rochette, and O. F. J. Vanparijs. 2003. Diagnosing Helminthiasis by Coprological Examination. 3rd ed. Beerse, Belgium: Janssen Animal Health.

Williamson, G. dan W. J.A. Payne. 1993 Pengantar Peternakan di Daerah Tropis. Edisi Ketiga (Terjemahan) Gajah Mada University Press. Yogyakarta.

Yabsley MJ. 2008. Capillarids Nematode. Editor: Carter T. Atkinson, Nancy J. Thomas, D. Bruce Hunter. Parasitic Diseases of Wild Birds. WileyBlackwell. USA. 